\title{
Perspectives of the Role of Chemotherapy in the Management of Osteosarcoma
}

\author{
Jyoti Bajpai $^{1^{*}}$, Norman Jaffe ${ }^{2}$ \\ ${ }^{1}$ Department of Medical Oncology, Tata Memorial Cancer Center, Mumbai, India; ${ }^{2}$ Children's Cancer Hospital, University of Texas \\ M. D. Anderson Cancer Center, Houston, USA. \\ Email: ${ }^{*}$ dr_jyotibajpai@yahoo.co.in
}

Received September $22^{\text {nd }}, 2012$; revised October $23^{\text {rd }}, 2012$; accepted November $4^{\text {th }}, 2012$

\begin{abstract}
Background: Multimodality management of osteosarcoma has significantly improved the 5 -year-survival rate for localized disease over the past 40 years: from 5\% - 10\% (in historical controls) to $65 \%-75 \%$ and $20 \%-30 \%$ in metastatic disease. These results were achieved with doxorubicin, cisplatin, high-dose methotrexate and ifosfamide (or cyclophosphamide). In the absence of new and effective agents the results have remained stationary for at least the past 30 years. No standard second line therapy exists for patients who relapse. In these circumstances surgery when feasible, constitutes the main therapeutic option. Questions/Purposes: To understand the present approach to therapy and determine the possibilities for improvement a review of the chemotherapeutic agents currently deployed in the treatment of Osteosarcoma was undertaken. Methods: The review focused on the results achieved with the evolution of therapy following the discovery of effective chemotherapeutic agents. Results: There was an improvement in survival during the first decade following the introduction of effective chemotherapy and limb salvage replaced amputation in the majority of patients. Attempts to rescue pulmonary metastases patients with surgical intervention were also enhanced but produced only minor improvement in survival. An international collaborative study, EURAMOS has been launched to investigate the utility of neoadjuvant chemotherapeutic agents in improving survival based upon their efficacy in the treatment of the primary tumor. Conclusions: New agents and or new strategies are urgently required to improve the outcome in Osteosarcoma.
\end{abstract}

Keywords: Osteosarcoma; Chemotherapy; Prognostic-Parameters

\section{Introduction}

In the current era long term survival in Osteosarcoma is achieved in approximately $66 \%$ of patients with localized extremity primaries and $25 \%-30 \%$ of patients with axial primaries or patients presenting with pulmonary metastases [1]. During the last three decades, treatment has stagnated with permutations and combinations of the few available effective agents: doxorubicin (DOX), highdose methotrexate with leucovorin "rescue" (MTX), cisdiaminedichloroplatium II (Cisplatin, [CDP]) and ifosfamide (IFX) or Cyclophosphamide (CTX). It is also uncertain if these agents are used in an optimal manner.

Some basic questions require further investigation. Principally, these include, but are not limited to, which "standard" chemotherapeutic agents alone or in combination could produce an optimal result; will alterations in the postoperative regimen improve the poor prognosis of patients with an initial unfavorable histological tumor response to neoadjuvant chemotherapy (NACT-see later)

*Corresponding author. and the role (if any) of immunomodulation?

This communication will provide a demarche of the principal chemotherapeutic agents in current use in the treatment of osteosarcoma. It will also briefly review other agents under investigation.

\section{Chemotherapy Discoveries during the Past Forty Years}

In the early 1970's two chemotherapeutic agents were found to be effective in treating metastatic osteosarcoma: DOX [2] and high dose MTX with leucovorin "rescue" [3]. Prior to that the Conpadri regimen devised by Sutow, was investigated. It comprised [pulsed] cyclophosphamide, vincristine (Oncovin), 1-phenylalanine mustard [4]. It yielded a 55\% disease-free survival. Sequential changes in the composition and acronym followed. MTX was incorporated and it was designated "Compadri", commencing with Compadri II. Each successive number indicated an evolution in the regimen [5] The Compadri II and III regimens yielded disappointing results. It was surmised that their lack of efficacy was due to reduced 
doses of doxorubicin, and the composition was adjusted in Compadri IV and Compadri V: MTX and DOX were intensified, and aggressive "front loading" was adopted. The results of Compadri I, II and III regimens revealed that 81 of 200 patients $(41 \%)$ were alive without evidence of disease, 18 months and longer after diagnosis [6]. Later, CDP and IFX administered with MESNA (which permitted its administration in high doses) were also found to be effective [7]. CTX a related alkylating compound with MESNA was also found to be useful as an alternative to IFX which could cause renal dysfunction [8]. Both agents are frequently used in combination with etoposide (ETP) [9]. Recent communications have also demonstrated responses with Gemcitabine (GEM) [9] and Cediranib (CED) [10].

\section{Neoadjuvant Chemotherapy}

Neoadjuvant chemotherapy (NACT) was initially introduced at the Memorial Sloan-Kettering Cancer Center (MSKCC) [1,11-13]. Chemotherapy agents were administered preoperatively and if effective, were maintained post operatively to destroy the putative pulmonary micrometastases; alternatively, if found ineffective alternative agents were introduced. Several consecutive series of investigations using a variety of chemotherapy regimens (T4, T5, T7, T10 and T12) [1,11-13] relating to this concept were published. The initial results in the landmark T10 NACT trial claimed a disease-free survival (DFS) of 93\% at a median follow-up of 20 months [9] and $76 \%$ at 7.75 years, which set the benchmark for other groups $[1,13]$.

\subsection{Prognostic Importance of Histological Response to Chemotherapy}

The introduction of NACT required histological examination of resected tumor specimens for evidence of response. This was accomplished by grading the degree of chemotherapy-induced tumor necrosis in a schema established by Huvos at MSKCC $[12,14]$. Responses were as graded as I (little or no effect), grade II (partial response, $\geq 50 \%$ necrosis), grade III ( $>90 \%$ necrosis), and grade IV (no viable tumor). Responses were also categorized as poor (grade I/II, $<90 \%$ necrosis) or good (III/IV, $\geq 90 \%$ necrosis. A 5-year event free survival (EFS) of $35 \%$ to $45 \%$ for poor responders and $70 \%$ to $80 \%$ for good responders was reported [13].

The Scandinavian Sarcoma Group and the Children's Cancer Study Group conducted similar multicenter studies (protocols SSG-II and CCSG-782, respectively) using the $\mathrm{T} 10$ regimen $[15,16]$. The overall survival (OS) and EFS rates were consistent between the two studies but inferior to the MSKCC results (Table 1).

The Cooperative Osteosarcoma Study group in Ger- many (COSS) also performed similar studies using polychemotherapy regimens [17]. COSS-86 study reported the best results using a five-drug regimen (DOX, MTX, CDP, ETP, and IFX). It yielded 10-year OS and EFS rates of $72 \%$ and $66 \%$, respectively. In addition, the Rizzoli Institute in Italy, using a similar five-drug regimen, achieved 5-year EFS of 63\% [18].

The collaborative European Osteosarcoma Intergroup (EOI) sought to use shorter dose-intense regimens in a series of large prospective, randomized, controlled studies [19-21] (Table 1). In addition, an alternative attempt was made to improve the prognosis by increasing the dose intensity with colony-stimulating factors and in so doing maximizing the therapeutic effect [21]. Although the proportion of good responders achieving $\geq 90 \%$ necrosis was increased in the dose-intense arm, it could not be translated into improved OS or EFS rates. The OS results remained inferior to those achieved in Germany, Italy, and the United States (Table 1). Recent studies have continued this approach $[17,22]$ but only one has shown it to be beneficial [22] (Table 2).

NACT was investigated by the Pediatric Oncology Group (POG) recruiting patients between 1986 and 1993 [23]. Patients were randomly assigned to receive (or not receive) NACT followed by surgery at week 10 or immediate surgery with adjuvant chemotherapy. The overall results demonstrated a 5 -year EFS of $65 \%$. No difference was evident between the two treatment arms. However, the amputation rate, nearly $50 \%$, was unacceptably high. Bacci et al. [24] expressed concern in regard to this study: patients had been denied comprehensive active cytotoxic agents $a b$ initio. Due to the very high amputation rate, they also suggested referral and centralization to a specialty for surgery for osteosarcoma.

\subsection{Intensification of Adjuvant Chemotherapy for Poor Responders}

The utility of NACT selecting an alternate chemotherapy regimen postoperatively for poor responders to improve the long-term survival remained unanswered. Further, early reports of the T10 regimen claimed that poor responders were actually salvaged by changing chemotherapy [13]; however a later publication of the 10-year results could not confirm the result [1]. Further, an attempt to test the hypothesis and the earlier claims were unable to replicate the results (Table 1) [16]. An explanation for this may be that the NACT response is a surrogate measure and an inherently biologic unresponsive tumor is not modifiable by currently available therapies.

\subsection{Intra-Arterial Chemotherapy}

During the next twenty to thirty alternative approaches employing existing agents were entertained. One consid- 
Table 1. Nonmetastatic extremity osteosarcoma: Neoadjuvant chemotherapy studies.

\begin{tabular}{|c|c|c|c|c|c|c|c|}
\hline Study & Type & Patients, $n$ & Chemotherapy & $\begin{array}{l}\text { Good } \\
\text { histological } \\
\text { responders }\end{array}$ & $\begin{array}{c}\text { Modification of a } \\
\text { djuvant-chemotherapy } \\
\text { by histological } \\
\text { Response? }\end{array}$ & Outcome & $\begin{array}{l}\text { Outcome better for } \\
\text { poor histological } \\
\text { responders by } \\
\text { changing adjuvant } \\
\text { chemotherapy? }\end{array}$ \\
\hline $\begin{array}{l}\text { MSKCC T7 } \\
(1992)[1,10]\end{array}$ & $\begin{array}{l}\text { Single } \\
\text { center }\end{array}$ & 75 & $\begin{array}{l}\text { Preop and postop: } \\
\text { BCD, MTX, V, D }\end{array}$ & $65 \%$ & No & 12-year DFS $72 \%$ & NA \\
\hline $\begin{array}{c}\text { MSKCC T10 } \\
(1982,1992) \\
{[1,10]}\end{array}$ & $\begin{array}{l}\text { Single } \\
\text { center }\end{array}$ & 153 & $\begin{array}{l}\text { Preop: MTX, V; } \\
\text { postop: D, P, BCD } \\
\text { (poor) or D, MTX, } \\
\text { BCD (good) }\end{array}$ & $34 \%$ & Yes & 5 -year DFS $72 \%$ & No \\
\hline $\begin{array}{l}\text { SSG-1 (T10) } \\
(1991)[12]\end{array}$ & Multicenter & 97 & $\begin{array}{l}\text { Preop: MTX, V; } \\
\text { postop: D, P, BCD } \\
\text { (poor) or D, MTX, } \\
\text { BCD (good) }\end{array}$ & $17 \%$ & Yes & $\begin{array}{c}5 \text {-year DFS } 54 \%, \\
5 \text {-year OS } 64 \%\end{array}$ & No \\
\hline $\begin{array}{l}\text { CCSG-782 } \\
\text { (T10) } \\
(1997)[13]\end{array}$ & Multicenter & 268 & $\begin{array}{l}\text { Preop: MTX, BCD; } \\
\text { postop: D, P, BCD } \\
\text { (poor) or D, MTX, } \\
\text { BCD (good) }\end{array}$ & $28 \%$ & Yes & $\begin{array}{c}\text { 8-year DFS 53\%, } \\
8 \text {-year OS } 60 \%\end{array}$ & No \\
\hline $\begin{array}{l}\text { COSS-86 } \\
(1998)[14]\end{array}$ & Multicenter & 171 & $\begin{array}{c}\text { Preop and postop: } \\
\text { MTX, D, P; } \\
\text { I (high-risk patients }\end{array}$ & $76 \%$ & No & $\begin{array}{c}10 \text {-year EFS } 66 \% \text {, } \\
10 \text {-year OS } 72 \%\end{array}$ & NA \\
\hline $\begin{array}{l}\text { Rizzoli study } 2 \\
\text { (1993) [15] }\end{array}$ & $\begin{array}{l}\text { Single } \\
\text { center }\end{array}$ & 164 & $\begin{array}{l}\text { Preop: MTX, D, P; } \\
\text { postop: MTX, D, } \\
\text { P (good) or MTX, D, } \\
\text { P, I, E (poor) }\end{array}$ & $71 \%$ & Yes & 5-year DFS 63\% & Yes \\
\hline $\begin{array}{l}\text { EOI study } 1 \\
\text { (1992) [16] }\end{array}$ & RCT & 198 & $\begin{array}{l}\text { Preop and postop: } \\
\text { P, D } \pm \text { MTX }\end{array}$ & $30 \%$ & No & $\begin{array}{c}\text { D, P: 5-year DFS } \\
\text { 57\%, 5-year OS 64\%; } \\
\text { D, P, MTX: 5-year } \\
\text { DFS 41\%, } \\
\text { 5-year OS 50\% }\end{array}$ & NA \\
\hline $\begin{array}{l}\text { EOI study } 2 \\
\text { (1997) [17] }\end{array}$ & $\mathrm{RCT}$ & 391 & $\begin{array}{l}\text { Preop: D, P or MTX, } \\
\text { D, V; postop: D, P or } \\
\text { MTX, D, V, BCD }\end{array}$ & $\begin{array}{c}\text { D, P } 30 \% \\
\text { multidrug } \\
29 \%\end{array}$ & No & $\begin{array}{c}5 \text {-year PFS } 44 \% \text {, } \\
5 \text {-year OS } 55 \%\end{array}$ & NA \\
\hline $\begin{array}{l}\text { EOI study } 3 \\
\text { (2003) [18] }\end{array}$ & $\mathrm{RCT}$ & 504 & $\begin{array}{l}\text { Preop and postop: } \\
\quad \mathrm{D}, \mathrm{P} \pm \mathrm{GCSF}\end{array}$ & $\begin{array}{l}\text { D, P } 36 \% \text {; D, } \\
\text { P, GCSF } 51 \%\end{array}$ & No & $\begin{array}{c}\text { D, P: } 5 \text {-year DFS } \\
\text { 37\%, 5-year OS 54\%; } \\
\text { D, P, GCSF: 5-year } \\
\text { DFS 40\%, 5-year OS } \\
56 \%\end{array}$ & NA \\
\hline $\begin{array}{l}\text { INT-0133 } \\
(2005)[19]\end{array}$ & $\mathrm{RCT}$ & 507 & $\begin{array}{l}\text { Preop and postop: } \\
\text { MTX, D, } \pm \mathrm{I}, \pm \\
\text { MTP-PE }\end{array}$ & Not reported & No & $\begin{array}{l}\text { 3-year EFS: D, P, } \\
\text { MTX 71\%; D, P, } \\
\text { MTX, MTP-PE 69\%; } \\
\text { D, P, MTX, I 60\%; } \\
\text { D, P, MTX, I, } \\
\text { MTP-PE 78\% }\end{array}$ & NA \\
\hline
\end{tabular}

BCD — bleomycin, cyclophosphamide, actinomycin D; COSS — Cooperative Osteosarcoma Study; D—doxorubicin; DFS—disease-free survival; E—etoposide; EFS - event-free survival; EOI — European, Osteosarcoma Intergroup; GCSF — granulocyte colony-stimulating factor; I-ifosfamide; IFN—interferon; MFS— metastasis-free survival; MSKCC - Memorial Sloan-Kettering Cancer Center; MTP-PE — muramyl tripeptide-phosphatidylethanolamine; MTX — methotrexate; NA — not applicable; OS - overall survival; P-cisplatin; PFS - progression-free survival; postop-postoperative;preop-preoperative; RCT-randomized controlled trial; SSG-Scandinavian Sarcoma Group; V-vincristine; PE-muramyl tripeptide-phosphatidylethanolamine; OS-overall survival; RCT-randomized controlled trial; SSG-Scandinavian Sarcoma Group.

eration was the administration of intra-arterial chemotherapy. The intent was to improve the local concentration of the drug at the tumor site to enhance its destructtion and prevent or reduce the incidence of local recur- rence. Simultaneously an attempt was made to maintain or enhance systemic tumoricidal concentrations to destroy pulmonary (micro) metastases. In the selection of agents, IFX and CTX were discarded. These agents 
Table 2. Studies of nonmetastatic extremity osteosarcomain which intensified neoadjuvant-chemotherapy is used aiming to increase the proportions of good histological-responders.

\begin{tabular}{ccccccc}
\hline Study & Type & Patients, $\boldsymbol{n}$ & Chemotherapy & Good responses & Outcome & $\begin{array}{c}\text { Intensification } \\
\text { found beneficial }\end{array}$ \\
\hline $\begin{array}{c}\text { COSS 86 (1998) } \\
{[14]}\end{array}$ & Multicenter & 171 & $\begin{array}{c}\text { Methotrexate, doxorubicin, } \\
\text { cisplatin, } \pm \text { ifosfamide } \\
\text { (in high-risk patients) }\end{array}$ & - & $\begin{array}{c}10 \text {-year EFS 66\%, } \\
10 \text {-year OS 72\% }\end{array}$ & No \\
$\begin{array}{c}\text { MSKCC T12 } \\
(1992)[1]\end{array}$ & RCT & 73 & $\begin{array}{c}\text { Methotrexate, BCD, } \\
\text { cisplatin, doxorubicin }\end{array}$ & $\begin{array}{c}\text { Standard arm 37\%, } \\
\text { intensified 44\% }\end{array}$ & $\begin{array}{c}5 \text {-year EFS 73\%, } \\
5 \text {-year OS 78\% }\end{array}$ & No \\
$\begin{array}{c}\text { INT-0133 (2005) } \\
{[19]}\end{array}$ & RCT & 507 & $\begin{array}{c}\text { Methotrexate, doxorubicin, } \\
\text { cisplatin } \pm \text { ifosfamide } \\
\text { and/or MTP-PE }\end{array}$ & Not reported & $\begin{array}{c}\text { 3-year EFS: standard } \\
71 \%, \text { ifosfamide, } \\
\text { MTP-PE 78\% }\end{array}$ & Yes \\
\hline
\end{tabular}

BCD — bleomycin, cyclophosphamide, actinomycin D; COSS - Cooperative Osteosarcoma Study; EFS—event-free survival; MSKCC-Memorial SloanKettering Cancer Center.

required phosphorylation in the liver to be activated and in their pristine form would be inactive if administered directly into the tumor feeding vessel. DOX was discarded since it was associated with skin and subcutaneous necrosis [25]. MTX achieved high tumoricidal concentrations intra-arterially but similar concentrations could also be attained via the intravenous route [26]. Intra-arterial CDP was therefore selected and found to be highly effective. Compared to the intravenous route responses were $60 \%$ in the former versus $30 \%$ in the latter [27]. It was utilized extensively at the MD Anderson Cancer Center in the TIOS pediatric trials with gratifying results [28].

Unfortunately, intra-arterial CDP is labor intensive. It is administered under general anesthesia or conscious sedation in a radiological suite under constant monitoring of the distal arterial pulses bilaterally during and after the infusion. Similar results may be achieved with several courses of combination chemotherapy administered by the intravenous route over a more prolonged period (weeks); this approach is thus generally preferred. However intra-arterial CDP may be particularly useful for treating tumors with pathologic fractures and tumor infiltrating into, or directly adjacent to, the neurovascular bundle. It is also helpful in attaining a rapid definitive attack against the primary tumor or local recurrence or when an urgent decision making therapeutic assessment is required. An example of the efficacy of intra-arterial treatment with CDP for local recurrence is illustrated in Figure 1.

\section{Other Therapies}

\subsection{Immunotherapy}

Liposome muramyl tripeptide-phosphatidyl ethanolamine (L-MTP-PE) is an immune compound capable of stimulating pulmonary macrophages to destroy metastases. It activates circulating monocytes and pulmonary macrophages to destroy (residual) tumor cells that are not eliminated by chemotherapy [26]. It was investigated

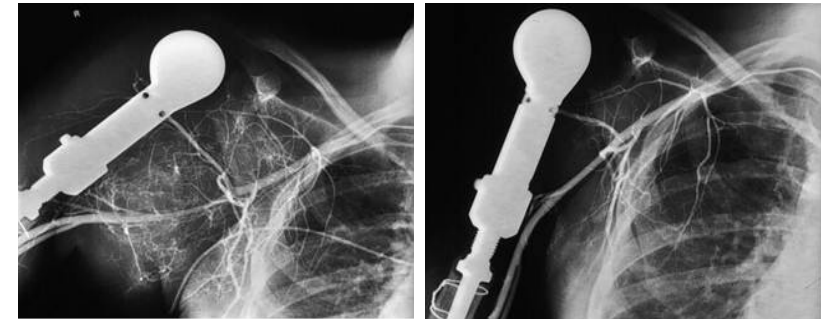

Figure 1. Osteosarcoma local recurrence. Response to repeat administration of intra-arterial cisplatin. Four (repeat) courses of intra-arterial cisplatin $\left(150 \mathrm{mg} / \mathrm{m}^{2}\right.$ per course every four weeks) were administered for a local recurrence to a patient with a humeral osteosarcoma. The patient had been previously treated with four similar courses of intraarterial cisplatin (150 $\mathrm{mg} / \mathrm{m}^{2}$ per course) every four weeks with $100 \%$ response. A limb salvages procedure was then performed followed by postoperative treatment with cisplatin, Methotrexate and Doxorubicin for one year. She developed the local recurrence approximately one year after completion of therapy (left panel). Repeat administration of intra arterial cisplatin again achieved a response as manifested by complete disappearance of tumor neovascularity and stain (right panel).

clinically in a controlled $2 \times 2$ factorial design randomized trial (INT-0133) [22]. Patients were initially randomized to receive IFX or IFX plus L-MTP-PE. In addition, patients also received DOX, MTX, and CDP. The results revealed that the combination IFX and L-MTPPE improved EFS. Treatment with IFX (and the combination DOX, CDP and MTX) was associated with a $71 \%$ and $64 \%$ probability EFS at 3 and 5 years respectively, whereas IFX and L-MTP-PE (and the combination) resulted in a $78 \%$ and $72 \%$ probability EFS at 3 and 5 years, respectively. L-MTP-PE has been licensed for use in Europe and is available in the United States on a compassionate IND (Investigational New Drug) [22,29].

The interferons, a group of cytokines with antiangiogenic and direct antitumor activity and immunostimulating properties have evoked considerable discussion. Most clinical information derives from Scandinavian series in 
which, with a median follow-up of 12 years, the observed 10-year metastasis-free and sarcoma specific survival rates were $39 \%$ and $43 \%$, respectively [30]. Toxicity was mainly constitutional and long-term toxicity was virtually absent. Interferon combined with etoposide has also produced responses in patients with pulmonary metastases [31].

\subsection{Targeted Therapy}

Tumor cells can be targeted for the delivery of monoclonal antibodies with specificities defined to inhibit key signals of tumor growth or survival. One of the first of this class of agents was antibodies targeting the epidermal growth factor receptor (EGFR) [32] and other members of the ERBB family, such as Her-2 [33]. Early work examined the biology of EGFR signaling and trafficking using osteosarcoma cell lines [34]; later, several groups identified Her-2 expression in osteosarcoma as a poor prognostic factor associated with increased metastases $[35,36]$. For several years there was controversy surrounding these observations particularly with inconsistent identification of the gene in osteosarcoma and publications of conflicting reports [37-39]. Most of these reports used methods designed to detect Her-2 in breast cancer in which gene amplification and overexpression (1 million - 2 million molecules per cell) were compared with normal levels of expression $(30,000-100,000$ molecules per cell). These were associated with a poor outcome $[35,36]$. In osteosarcoma, the relevant comparison is between modest expression (20,000 - 50,000 molecules per cell) compared with absent expression, and therefore, more sensitive methods are probably required. Several (later) methods possibly confirmed that osteosarcoma cell lines do express EGFR, Her-2 and Her-4 [39]; these receptors are constitutively phosphorylated [40], suggesting their meaningful role in tumor pathogenesis.

EGFR has been also used using adenoviral vectors in experimental models [41]. The literature suggests that $80 \%$ of osteosarcoma tumors are expected to express EGFR, although much of this expression may be cytoplasmic [39], and only about half will demonstrate dense membranous expression by immunohistochemistry [42].

The Children's Oncology Group (COG) launched a clinical trial using trastuzumab (anti-Her-2 MAb) in combination with standard chemotherapy for high-risk metastatic osteosarcoma. The study completed accrual but the outcome has not been published. It appears that the administration of anti-Her-2 monoclonal antibodies in combination with traditional chemotherapy for children is safe. Anti-EGFR medications have also been administered safely to children. It may be presumed that antibodies directed against the ERBB family would be effective carriers of selective antitumor drugs, providing targeted therapy for osteosarcoma.

\subsection{Nanoparticles}

Nanoparticles may also be an effective way of delivering targeted therapy for osteosarcoma. In the laboratory setting, various forms of nucleic acids, including siRNA, shRNA and catalytic nucleic acids such as DNAzymes, have been used with great efficacy specifically to downregulate particular genes within cancer cells. In resistant metastatic osteosarcoma patients a Phase I and Phase II study of Rexin-G a pathotropic nano-particle produced a median progression-free survival exceeding 3 months with a median overall survival of nearly 7 months [43]. Dass et al. have shown that more broadly applicable chitosan nanoparticles bearing DNAzymes specific for c-Jun can sensitize resistant osteosarcoma to doxorubicin [44].

\subsection{Samarium and Bisphosphonates}

Symptomatic relief of pain in bone metastases has generally been accomplished with radiation therapy. In this setting it may be juxtaposed to MTX or combined with GEM as a radiosensitzer $[45,46]$. An additional means of providing targeted therapy to bone is to exploit the unique affinity of bone for phosphates and phosphonates. These chemical conjugates can be used to deliver treatment doses of radiation to sites of bone metastasis and other sites of bone turnover [47]. This has been done effectively with samarium-153 ethylene-diamine-tetramethylene-phosphonate (Samarium, $153 \mathrm{Sm}$, or Quadramet). This agent was initially developed to palliate painful bone metastasis [43]. Myelotoxicity is the predominant dose-limiting toxicity, although this usually is manageable even in combination with external beam radiotherapy [48].

The same chemical affinity of phosphonates for newly formed bone provides the basis for the effectiveness of bisphosphonates in limiting osteoclastic bone resorption in osteoporosis [49]. Nitrogen-containing bisphosphonates such as zoledronic acid inhibit the mevalonic acid synthesis pathway, which is essential for synthesizing the prenyl adjunct farnesyl. Inhibition of prenylation usually induces cell death as it provides an essential lipid anchor to many signaling molecules, including Ras [50]. The net effect is reduced osteoclast function and reduced bone resorption. Bisphosphonates are effective in reducing the progression of bone metastases in several carcinomas, and can provide symptomatic pain relief [51]. This effect led to their approval by the FDA for treating bone metastasis in cancer, irrespective of the histological type.

$\mathrm{COG}$ is assessing the feasibility of incorporating bisphosphonate with conventional MAP (MTX, DOX 
and $\mathrm{CDP}$ ) in patients with newly diagnosed high-risk osteosarcoma. It is noteworthy that osteosarcoma, by definition, creates new bone within tumors. Provided the conjugates are not toxic to normal osteoclasts and marrow components, and since bisphosphonates and tetraphosphonates target these compounds in newly formed bone, the targeting effect could possibly be harnessed to deliver new therapeutics at higher concentrations within growing tumors.

\section{Other Possible Emerging Therapies with Conventional Agents}

Other compounds which have undergone testing include the taxanes as single agents [52] and the DNA minor groove inhibitor trabectidin. In a study utilizing the latter, of a total of 23 evaluable patients there were three minor responses, a disappointing result considering the anecdotal reports of trabectidin's activity in osteosarcoma, when the drug was first introduced [53].

Phase II studies of patients with relapsed disease are planned to evaluate combinations of GEM and docetaxel and GEM and oxaliplatin. Single-agent data for each of these three agents have either been sporadically positive or negative or not systematically studied [54]. Carboplatin has been used in several combination regimens including an intra-arterial administration [55]. Since other agents in addition to carboplatin were employed, the contribution of the latter to the final result cannot be assessed.

Novel antifolate agents, including trimetrexate, have been investigated in patients who have had relapses; they have not been evaluated in formal clinical trials.

Patients previously treated with conventional doses of IFX $\left(9 \mathrm{G} / \mathrm{M}^{2}\right)$, upon relapse, may again achieve a response by escalating the dose to $14 \mathrm{G} / \mathrm{M}^{2}$ and should a subsequent relapse again occur, to $17.5 \mathrm{G} / \mathrm{M}^{2}$ (Jaffe N, unpublished data). This experience deserves further study. Because of the possibility of renal damage the $17.5 \mathrm{G} / \mathrm{M}^{2}$ should be limited to three courses (one course every four weeks). Each course of $17.5 \mathrm{G} / \mathrm{M}^{2}$ is administered as 3.5 $\mathrm{G} / \mathrm{M}^{2}$ per day $\times 5$ with MESNA and hematological support for myelosuppression. An example a response in these circumstances is depicted in Figure 2.

\subsection{Inhalation Chemotherapy}

Liposomal 9NC has been investigated as inhalation therapy for the treatment of pulmonary metastases. The strategy did not produce any responses in a limited number of patients (Kleinerman $\mathrm{E}$ and Jaffe $\mathrm{N}$, unpublished data). Aerosol therapy targeting the Fas/FasL pathway and pulmonary metastases is being investigated by Kleinerman. Granulocyte-Monocyte Colony Stimulating Factor (GM-CSF) for the first pulmonary recurrence was

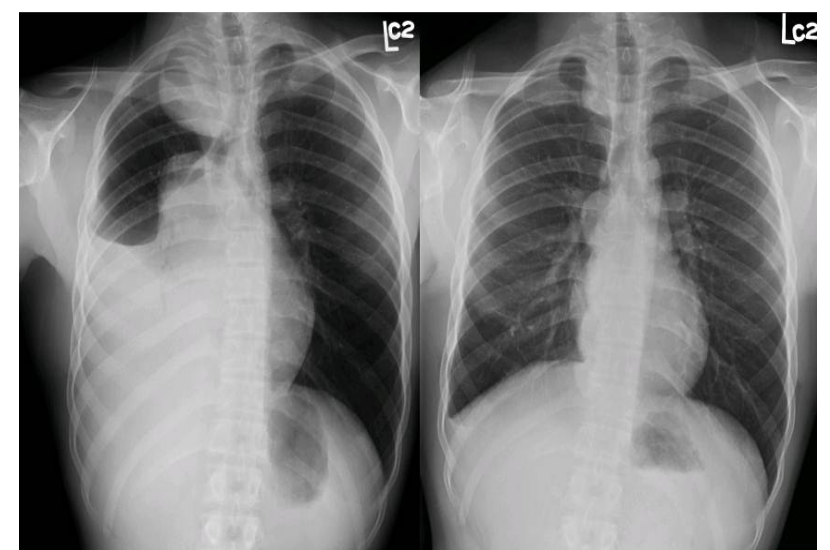

Figure 2. Response to high dose ifosfamide. The patient presented with an osteosarcoma of the femur and pulmonary metastases. He was treated with cisplatin, Methotrexate and doxorubicin. He achieved an excellent response in the primary tumor ( $>95 \%$ tumor necrosis) and disappearance of most pulmonary metastases. The persistent metastases were resected. He developed recurrent pulmonary metastases which responded to four courses of ifosfamide (9 $\mathrm{g} / \mathrm{m}^{2}$ per course). He again developed pulmonary metastases which similarly responded to four courses of a higher dose of IFX (14 g/m $\mathrm{m}^{2}$ per course). Four weeks after the last course of Ifosfamide, pending a repeat thoracotomy to remove a few persistent metastases he developed an exaggeration of the pulmonary relapse as manifested by a right sided pleural effusion and an underlying pulmonary lesion (left panel). This responded dramatically to a higher dose of ifosfamide (17.5 $\mathrm{g} / \mathrm{m}^{2}$ per course) as also a persistent enlarging metastasis in the right upper hemi thorax (right panel). Four courses of Ifosfamide (each course comprising 3.5 $\mathrm{g} / \mathrm{m}^{2} /$ day $\times 5$ ) were administered.

investigated by COG. The strategy did not result in an immunostimulatory effect on pulmonary metastases to improve the outcome post relapse [56]. A Phase Ib/IIa study of sustained release lipid inhalation targeting cisplatin by inhalation in the treatment of patients with relapsed/progressive osteosarcoma metastatic to the lung was reported by Chou A. J. Three of eight patients with less bulky disease sustained benefit [57].

\subsection{Salvage Chemotherapy in a Relapse Setting in Osteosarcoma}

The outcome in patients who relapse with pulmonary metastases depends upon time and site of relapse. Late relapse, the presence of unilateral, solitary lesions and the absence of pleural disruption are favorable features $[58,59]$. The prognosis of patients, who relapse with bone metastases, unless they are a single late appearing metastasis, is worse than that of patients who first relapse with lung metastases [60].

Studies have shown that it is possible to obtain prolonged survival and cure in about $1 / 4$ of relapsing patients with aggressive treatments. Complete surgery is an 
essential component of curative second-line therapy. Poly-chemotherapy may contribute to limited improvements. IFX and ETP were found highly active in recurrent sarcomas [61]; GEM and docetaxel in combination were also shown to have activity [62]. A phase II trial found that CTX and ETP arrested disease progression in a significant number of patients (54\%) which translated to a better OS with a favorable toxicity profile [63]. High dose chemotherapy comprising carboplatin and ETP (two courses) followed by stem-cell rescue combined with surgery induced a complete response in a portion of patients who were chemosensitive to induction treatment; however most patients again relapsed [64].

\subsection{High Dose Methotrexate}

This perspective would be incomplete without addressing the frequent scrutiny that has been applied to MTX. Unlike any other agent it is the only drug that has been subjected to a randomized trial to test its efficacy against an effective agent. This communication constituted the basis of a Cochrane review on MTX and osteosarcoma [65]. It was shown to be inferior to intra-arterial CDP in the treatment of the primary tumor [66]. As the sole agent in adjuvant treatment it increased survival to $40 \%$ $60 \%$ [67] compared to $5 \%-20 \%$ in historical controls, and in combination with other agents (pre- and postoperative therapy), to $65 \%-75 \%[26,68-71]$. When juxtaposed to, or utilized in combination with radiation therapy, it potentiated the action of radiation therapy. In this circumstance it contributed to eradicating pulmonary metastases and provided appreciative palliation for metastases in bone, soft tissue and vital organs. An example of cavitations produced by radiation therapy and MTX in pulmonary metastases is depicted in Figure 3.

MTX is usually administered over 4 to 6 hours, and it is generally considered that a mean peak serum MTX threshold greater than 700 to $1000 \mu \mathrm{mol} / \mathrm{L}$ at the completion of the infusion is required for successful therapy. This was found to correlate significantly with prognosis [72]. However, superior results are more likely to be achieved with levels in excess of $1500 \mu \mathrm{mol} / \mathrm{L}$ (Jaffe N, unpublished data). For undetermined reasons there is inter- and intra-patient variability and high tumoricidal concentrations with each course may not always be obtained.

A regimen devoid of MTX (non methotrexate-based therapy) was documented to be among the "major poor prognostic factors" [71]. Using serum MTX concentrations to monitor MTX levels, the regimen have been successfully administered safely and effectively [26, 68-72]. Prerequisites for therapy include normal renal and hepatic function, a normal hemogram, and absence of infection. Pleural, pericardial and peritoneal effusions

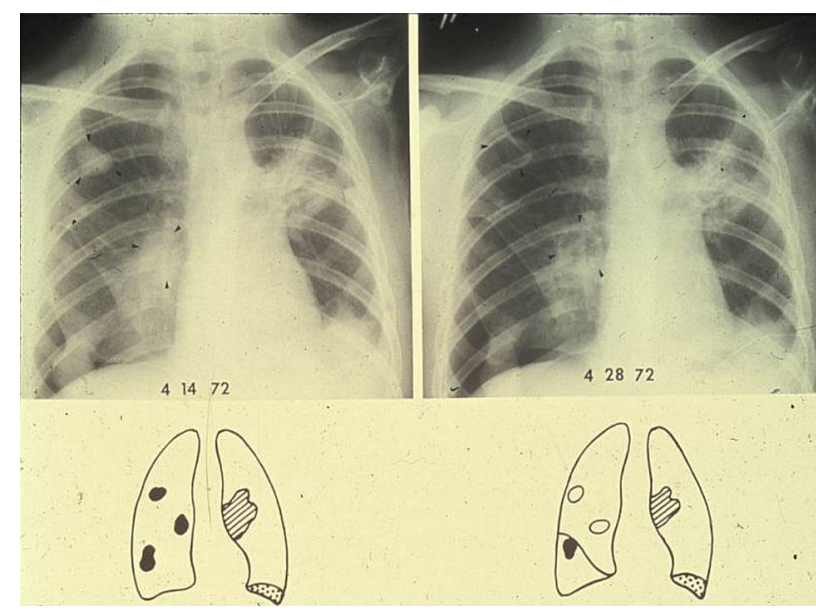

Figure 3. Osteosarcoma with recurrent pulmonary metastases. Response to Radiation therapy and a 24 hour infusion of High dose Methotrexate. Right panel: The patient with localized primary osteosarcoma of the humerus was treated with an immediate amputation. He developed pulmonary metastases while receiving four post-operative 6-hour methotrexate infusions $\left(12.5 \mathrm{~g} / \mathrm{m}^{2}\right)$. Pulmonary radiation therapy was administered ( 2400 rad) followed by an additional 6-hour course of methotrexate. The pulmonary metastases disappeared. Maintenance 6-hour methotrexate treatment $\left(12.5 \mathrm{~g} / \mathrm{m}^{2}\right)$ was reinstated. He again developed recurrent disease: three nodules are present in the right hemithorax, two within the pulmonary parenchyma (arrow heads) and one at the right base where a small pneumothorax is also present. Residual fibrosis from prior methotrexate-radiation therapy is present in the left hilar region where a single metastasis had been treated. A left basal small pleural effusion is also present. Left panel: After additional treatment with radiation therapy (1000 rad) and a single 24-hour methotrexate infusion $\left(12.5 \mathrm{~g} / \mathrm{m}^{2}\right)$ juxtaposed to the completion of radiation therapy, cavitation of the two pulmonary lesions in the right hemithorax was achieved (arrow heads). There was a slight reduction in the size of the metastatic nodule at the base of the right hemithorax. There was no change in the residual fibrotic lesion in the left hemithorax and the left basal pleural effusion.

may cause a delay in MTX excretion by sequestering the drug into the fluid and are contraindicated in treatment [73]. Antibiotics excreted by the renal tubules may compete with MTX excretion and contribute to toxicity, Salicylates and proton pump inhibitors have also been implicated.

A MTX level of $0.1 \mu \mathrm{mol} / \mathrm{L}$ is generally considered safe for discontinuation of leucovorin rescue although $<0.3 \mu \mathrm{mol} / \mathrm{L}$ has also been adopted (Jaffe N Personal experience). These levels are usually attained at 72 hours. Toxic reactions are infrequent. They are generally induced by incomplete (delayed) renal clearance and are often associated with MTX precipitation in the renal tubules. This reaction manifests with gastrointestinal mucosal ulceration, myelosuppression, and hepatorenal failure. Measures for aborting or treating toxic reactions may 
comprise any or all of the following [73]:

1) Increasing fluid intake to $4 \mathrm{~L} / \mathrm{m}^{2} / 24 \mathrm{~h}$.

2) Increasing leucovorin dose to $50-100 \mathrm{mg}$ (or higher) every $6 \mathrm{~h}$, as stipulated by an institution's algorithm.

3) Carboxypeptidase $G^{2}$ (glucarpidase) if the serum 24- or 48-h MTX level is inordinately higher than usually encountered and/or anuria or oliguria appears to be developing.

4) High-flux renal dialysis at any time in the above circumstances.

\subsection{Prognostic Parameters of Tumor Response to Chemotherapy}

Prognostic markers especially noninvasive predictors for disease outcome in osteosarcoma are urgently required to predict response to chemotherapy. Necrosis determined by histological examination is an established robust prognostic marker [13] and seems to reflect either the effectiveness of the chemotherapy regimen or the properties inherent to some tumors that make them intrinsically more or less responsive. However, as necrosis can only be assessed after completion of neoadjuvant chemotherapy, there is a risk of developing resistant clones with prolonged continuation of preoperative ineffective chemotherapy. Thus, it is desirable to establish non-invasive imaging surrogates (or other mechanisms) to predict response to NACT.

Noninvasive markers to assess tumor response include PET-CT parameters. These comprise anatomical studies (pre- and post-NACT volumes and change); metabolic investigations (pre-NACT SUV max and post-NACT SUV ratios), and newly derived composite markers (preand post-NACT metabolic burden, SUV $\times$ volume and change). Their ability to predict histological response with improved precision would be invaluable [74]. Conventional and diffusion weighted MRI parameters also suggest the ability to predict response. In the latter study, a new parameter, diffusion per unit volume (apparent diffusion coefficient adjusted for volume), could be derived [75].

Post NACT, VEGF expression in surviving tumor cells appears to be an important negative therapeutic prognostic factor and may assist identification of future strategies according to the angiogenic potential of the disease [76]. Further, it was found that dynamic-contrastenhanced-MRI (DCE-MRI) has an important role as a noninvasive imaging surrogate of tumor angiogenesis based on visual inspection of time-intensity-curves (TIC): the change in curve pattern from washout/plateau to persistent type was found to be in agreement with corresponding decrease in microvascular permeability, i.e. VEGF expression [77].

\subsection{Surgical Advances in Association with Chemotherapy}

The demonstration that chemotherapy was effective in osteosarcoma prompted its use not only to destroy the putative pulmonary micrometastases but also to treat the primary tumor prior to surgical ablation. The objective was to improve the opportunity for local control and prevent local recurrence particularly in limb salvage, the demand for which increased exponentially with improved survival. Criteria for limb salvage eligibility were formalized (Table 3).

\subsection{Present Status of Chemotherapy in Osteosarcoma}

Review of adjuvant and neoadjuvant studies suggests that any further improvements in survival in osteosarcoma by modification of chemotherapy are likely to be small. Large numbers of patients will need to be enrolled in future studies, which, given the rarity of the disease, highlights the need for international collaboration To this end, the European, and American Osteosarcoma study (EURAMOS1) was formed as a collaborative venture among the United States, United Kingdom, and Europe. It comprises the combined recourses of COG, COSS, EOI, and SSG [78]. The study, INT-0133 [22], is designed to determine if the outcome of poor and good responders can be improved by modification of NACT. All patients receive NACT: MAP (MTX, DOX [Adriamycin]

Table 3. Eligibility criteria for limb-salvage surgery.

\begin{tabular}{|c|c|}
\hline Factor & Impact on Decision \\
\hline Lower extremity tumor & $\begin{array}{l}\text { Maximum/near maximum linear } \\
\text { growth } \\
\text { Alternatively: Consider } \\
\text { expandable prosthesis, van Ness } \\
\text { rotationplasty or other options }\end{array}$ \\
\hline Upper extremity & Individual consideration \\
\hline Biopsy & Properly placed \\
\hline Neurovascular bundle & Non involvement by tumor \\
\hline $\begin{array}{l}\text { Pulmonary metastases or } \\
\text { pathological fracture }\end{array}$ & Not a contradiction \\
\hline Psychological acceptance & $\begin{array}{l}\text { Essential; if preoperative therapy } \\
\text { fails, amputation will be required }\end{array}$ \\
\hline Small tumor & Ideal \\
\hline $\begin{array}{l}\text { Full discussion of nature, } \\
\text { (advantages and disadvantages), } \\
\text { complications and long term } \\
\text { outcome of limb salvage as } \\
\text { compared to amputation }\end{array}$ & $\begin{array}{l}\text { Completely understood and } \\
\text { accepted }\end{array}$ \\
\hline
\end{tabular}


and CDP) is administered in the control arm. Poor responders are randomized to receive MAP with or without IFX and ETP. Good responders continue on MAP and are randomized to maintenance pegylated interferon or observation. In contrast with previous studies, EURAMOS1 includes axial and extremity tumors and patients with metastatic disease. Parallel biologic studies are included.

A recent meta-analysis publication in patients with localized high-grade osteosarcoma endorses the EURAMOS strategy [79]. Salvage of poor responders by changing drugs, or intensifying treatment postoperatively was not shown to be useful in this analysis. In view of these results the outcome of EURAMOS1 is anticipated with great interest. Other observations in the meta-analysis noted that nine historical studies confirmed a long-term survival of $16 \%$ after only local treatment. Fifty single agent phase II studies showed high response rates for DOX (43\%), IFX 33\%), M (32\%), CDP (26\%) and only $4 \%$ for ETO [80].

\section{Conclusion}

Major advances in treatment with chemotherapy have produced significant improvement in survival in patients with osteosarcoma and the ability to perform limb salvage in many newly diagnosed patients. Unfortunately survival has not improved over the past forty years. New discoveries and the application of effective chemotherapy are an urgent requirement for further advancement.

\section{REFERENCES}

[1] P. A. Meyers, G. Heller, J. Healey, A. Huvos, J. Lane and R. Marcove, "Chemotherapy for Nonmetastatic Osteogenicsarcoma: The Memorial Sloan-Kettering Experience," Journal of Clinical Oncology, Vol. 10, 1992, pp. 5-15.

[2] G. Bonadonna, S. Monfardini, M. De Lena, F. FossatiBellani and G. Beretta, "Phase I and Preliminary Phase II Evaluation of Adriamycin (NSC/123127)," Cancer Research, Vol. 30, 1970, pp. 2527-2582.

[3] N. Jaffe, "Recent Advances in the Chemotherapy of Osteogenicsarcoma," Cancer, Vol. 30, 1972, pp. 1627-1631. doi:10.1002/1097-0142(197212)30:6<1627::AID-CNCR2 $820300631>3.0 . \mathrm{CO} ; 2-\mathrm{H}$

[4] W. W. Sutow, "Combination Chemotherapy with Adriamycin (NSC-123127) in Primary Treatment of Osteogenicsarcoma (Part III)," Cancer Chemotherapy Reports, Vol. 6, 1975, pp. 315-317.

[5] W. W. Sutow, E. A. Gehan and P. C. Dyment, "MultiDrug Adjuvant Chemotherapy in Osteosarcoma. Interim Report of the Southwest Oncology Group Studies," Cancer Chemotherapy Reports, Vol. 62, No. 2, 1978, pp. 265-269.

[6] J. Herson, W. W. Sutow, K. Elder, T. J. Vietti, J. M. Fal- letta and W. M. Crist, "Adjuvant Chemotherapy in Non Metastatic Osteosarcoma: A Southwest Oncology Group Study," Medical and Pediatric Oncology, Vol. 8, No. 4, 1980, pp. 343-352. doi:10.1002/mpo.2950080405

[7] T. Philip, C. Iliescu, M. C. Demaille, H. Pacquement, J. C. Gentet and I. Krakowski, "High-Dose Methotrexate and HELP [Holoxan (Ifosfamide), Eldesine (Vindesine), Platinum]-Doxorubicin in Non-Metastatic Osteosarcoma of the Extremity: A French Multicentre Pilot Study," Annals of Oncology, Vol. 10, No. 9, 1999, pp. 1065-1071. doi:10.1023/A:1008395126800

[8] N. Jaffe, "Osteosarcoma: Review of the Past, Impact on the Future: The American Experience Pediatric and Adolescent Osteosarcoma," Cancer Treatment and Research, Vol. 152, 2010, pp. 239-262. doi:10.1007/978-1-4419-0284-9 12

[9] K. M. Leu, L. J. Ostruszka, D. Shewach, M. Zalupski, V. Sondak and J. S. Biermann, "Laboratory and Clinical Evidence of Synergistic Cytotoxicity of Sequential Treatment with Gemcitabine Followed by Docetaxel in the Treatment of Sarcoma," Journal of Clinical Oncology, Vol. 22, No. 9, 2004, pp. 1706-1712. doi:10.1200/JCO.2004.08.043

[10] E. Fox, R. Aplenc, R. Bagatell, M. K. Chuk, E. Dombi and W. Goodspeed, "A Phase 1 Trial and Pharmakinetic Study of Cediranib, an Orally Bioavailable Pan-Vascular Endothelial Growth Factor Receptor Inhibitor, in Children and Adolescents with Refractory Solid Tumors," Journal of Clinical Oncology, Vol. 28, No. 35, 2010, pp. 5174-5181. doi:10.1200/JCO.2010.30.9674

[11] G. Rosen, M. L. Murphy, A. G. Huvos, M. Gutierrez and R. C. Marcove, "Chemotherapy, En bloc Resection, and Prosthetic Bone Replacement in the Treatment of Osteogenicsarcoma," Cancer, Vol. 37, No. 1, 1976, pp. 1-11. doi:10.1002/1097-0142(197601)37:1<1::AID-CNCR2820 370102>3.0.CO;2-3

[12] G. Rosen, R. C. Marcove, B. Caparros, A. Nirenberg, C. Kosloff and A. G. Huvos, "Primary Osteogenicsarcoma: The Rationale for Preoperative Chemotherapy and Delayed Surgery," Cancer, Vol. 43, No. 6, 1979, pp. 2163 2177.

doi:10.1002/1097-0142(197906)43:6<2163::AID-CNCR2 820430602>3.0.CO;2-S

[13] G. Rosen, B. Caparros, A. G. Huvos, C. Kosloff, A. Nirenberg and A. Cacavio, "Preoperative Chemotherapy for Osteogenicsarcoma: Selection of Postoperative Adjuvant Chemotherapy Based on the Response of the Primary Tumor to Preoperative Chemotherapy," Cancer, Vol. 49, No. 6, 1982, pp. 1221-1230.

doi:10.1002/1097-0142(19820315)49:6<1221::AID-CNC R2820490625>3.0.CO;2-E

[14] A. G. Huvos, G. Rosen and R. C. Marcove, "Primary Osteogenicsarcoma: Pathologic Aspects in 20 Patients after Treatment with Chemotherapy, En bloc Resection, and Prosthetic Bone Replacement," Archives of Pathology \& Laboratory Medicine, Vol. 101, No. 1, 1977, pp. 14-18.

[15] G. Saeter, T. A. Alvegård, I. Elomaa, A. E. Stenwig, T. Holmström and O. P. Solheim, "Treatment of Osteosar- 
coma of the Extremities with the T-10 Protocol, with emphasis on the Effects of Preoperative Chemotherapy with Single-agent High-dose Methotrexate: A Scandinavian Sarcoma Group Study," Journal of Clinical Oncology, Vol. 9, No. 10, 1991, pp. 1766-1775.

[16] A. J. Provisor, L. J. Ettinger, J. B. Nachman, M. D. Krailo, J. T. Makley and E. J. Yunis, "Treatment of Nonmetastatic Osteosarcoma of the Extremity with Preoperative and Postoperative Chemotherapy: A Report from the Children's Cancer Group," Journal of Clinical Oncology, Vol. 15, No. 1, 1997, pp. 76-84.

[17] N. Fuchs, S. S. Bielack, D. Epler, P. Bieling, G. Delling and D. Körholz, "Long-Term Results of the Co-Operative German-Austrian-Swiss Osteosarcoma Study Group's Protocol COSS-86 of Intensive Multidrug Chemotherapy and Surgery for Osteosarcoma of the Limbs," Annals of Oncology, Vol. 9, No. 8, 1998, pp. 893-899. doi:10.1023/A:1008391103132

[18] G. Bacci, P. Picci, S. Ferrari, P. Ruggieri, R. Casadei and A. Tienghi, "Primary Chemotherapy and Delayed Surgery for Nonmetastatic Osteosarcoma of the Extremities: Results in 164 Patients Preoperatively Treated with High Doses of Methotrexate Followed by Cisplatin and Doxorubicin," Cancer, Vol. 72, No. 11, 1993, pp. 3227-3238. doi:10.1002/1097-0142(19931201)72:11<3227::AID-CN CR2820721116>3.0.CO;2-C

[19] V. H. Bramwell, M. Burgers, R. Sneath, R. Souhami, A. T. van Oosterom and P. A. Voûte, "A Comparison of Two Short Intensive Adjuvant Chemotherapy Regimens in Operable Osteosarcoma of Limbs in Children and Young Adults: The First Study of the European Osteosarcoma Intergroup," Journal of Clinical Oncology, Vol. 10, No. 10, 1992, pp. 1579-1591.

[20] I. J. Lewis, M. A. Nooij, J. Whelan, M. R. Sydes, R. Grimer and P. C. Hogendoorn, "MRC BO06 and EORTC 80931 Collaborators; European Osteosarcoma Intergroup: Randomized Trial of Two Regimens of Chemotherapy in Operable Osteosarcoma: A Study of the European Osteosarcoma Intergroup," Lancet, Vol. 350, No. 9082, 1997, pp. 911-917.

[21] I. J. Lewis and M. Nooij, "Chemotherapy at Standard or Increased Dose Intensity in Patients with Operable Osteosarcoma of the Extremity; a Randomized Controlled trial Conducted by the European Osteosarcoma Intergroup (ISRCTN 86294690)," Proceedings of the Annual Meeting of the American Society of Clinical Oncology, Chicago, 31 May-3 June 2003.

[22] P. A. Meyers, C. L. Schwartz, M. Krailo, E. S. Kleinerman and D. Betcher, "Osteosarcoma: A Randomized, Prospective Trial of the Addition of Ifosfamide and/or Muramyl Tripeptide to Cisplatin, Doxorubicin, and HighDose Methotrexate," Journal of Clinical Oncology, Vol. 26, No. 18, 2005, pp. 2004-2011. doi:10.1200/JCO.2005.06.031

[23] A. M. Goorin, D. J. Schwartzentruber, M. Devidas, M. C. Gebhardt, A. G. Ayala, M. B. Harris and Pediatric Oncology Group, "Presurgical Chemotherapy Compared with Immediate Surgery and Adjuvant Chemotherapy for Nonmetastatic Osteosarcoma: Pediatric Oncology Group Study POG-8651," Journal of Clinical Oncology, Vol. 21,
No. 8, 2003, pp. $1574-1580$. doi:10.1200/JCO.2003.08.165

[24] G. Bacci, S. Ferrari, A. Longhi, C. Forni, P. Ruggieri and A. Briccoli, "Preoperative Therapy versus Immediate Surgery in Nonmetastatic Osteosarcoma," Journal of Clinical Oncology, Vol. 21, No. 24, 1993, pp. 4662-4663. doi:10.1200/JCO.2003.99.157

[25] N. Jaffe, H. Watts, K. E. Fellows and G. Vawter, "Local En bloc Resection for Limb Preservation," Cancer Treatment and Research, Vol. 62, No. 2, 1978, pp. 217-223.

[26] N. Jaffe, A. K. Raymond, A. Ayala, S. Wallace, C. H. Carrasco and Y. M. Wang, "Analysis of the Efficacy of Intra-Arterial Cis-Diammine-Dichloroplatinum-II and HighDose Methotrexate with Citrovorum Factor Rescue in the Treatment of Primary Osteosarcoma," Regional Cancer Treatment, Vol. 2, 1989, pp. 157-163.

[27] N. Jaffe, D. Jaffe, A. Raymond, P. Pearson, R. Robertson and E. Kim, "Pediatric Osteosarcoma: Treatment of the Primary Tumor with Intravenous Cis diamminedichloroplatinum-II (CDP). Comparison of the Results with the Reported Efficacy of Intra-arterial CDP," International Journal of Oncology, Vol. 3, 1993, pp. 273-278.

[28] N. Jaffe, J. Knapp, V. P. Chuang, S. Wallace, A. Ayala and J. Murray, "Osteosarcoma Intra-Arterial Treatment of the Primary Tumor with Cis-DiamminedichloroplatinumII (CDP). Angiographic, Pathologic and Pharmacologic Studies," Cancer, Vol. 51, 1983, pp. 402-407. doi:10.1002/1097-0142(19830201)51:3<402::AID-CNCR 2820510308>3.0.CO;2-P

[29] E. S. Kleinerman, "Biologic Therapy for Osteosarcoma using Liposome-encapsulated Muramyl Tripeptide," Hematology/Oncology Clinics of North America, Vol. 9, No. 4, 1995, pp. 927-938.

[30] C. R. Müller, S. Smeland, H. C. Bauer, G. Saeter and H. Strander, "Interferon Alpha as the Only Adjuvant Treatment in High-Grade Osteosarcoma: Long Term Results of the Karolinska Hospital Series," Acta Oncologica, Vol. 44, No. 5, 2005, pp. 475-480. doi: $10.1080 / 02841860510029978$

[31] L. L. Worth, N. Jaffe, R. S. Benjamin, N. E. Papadopoulos, S. Patel and A. K. Raymond, "Phase II Study of Recombinant Interleukin $1 \alpha$ and Etoposide in Patients with Relapsed Osteosarcoma," Clinical Cancer Research, Vol. 3, 1997, pp. 1721-1729.

[32] H. Masui, T. Kawamoto, J. D. Sato, B. Wolf, G. Sato and J. Mendelsohn, "Growth Inhibition of Human Tumor Cells in Athymic Mice by Anti-Epidermal Growth Factor Receptor Monoclonal Antibodies," Cancer Research, Vol. 44, No. 3, 1984, pp. 1002-1007.

[33] R. M. Hudziak, G. D. Lewis, M. Winget, B. M. Fendly, H. M. Shepard and A. Ullrich,"p185HER2 Monoclonal Antibody Has Antiproliferative Effects in Vitro and Sensitizes Human Breast Tumor Cells to Tumor Necrosis Factor," Molecular and Cellular Biology, Vol. 9, No. 3, 1989, pp. 1165-1172.

[34] Y. Hirata, M. Uchihashi, H. Nakashima, T. Fujita, S. Matsukura and K. Matsui, "Specific Receptors for Epidermal Growth Factor in Human Bone Tumour Cells and Its Effect on Synthesis of Prostaglandin E2 by Cultured 
Osteosarcoma Cell Line," Acta Endocrinologica (Copenhagen), Vol. 107, 1984, pp. 125-130.

[35] S. Ferrari, F. Bertoni, L. Zanella, E. Setola, P. Bacchini and M. Alberghini, "Evaluation of P-Glycoprotein, HER2/ErbB-2, p53, and Bcl-2 in Primary Tumor and Metachronous Lung Metastases in Patients with High-Grade Osteosarcoma," Cancer, Vol. 100, No. 9, 2004, pp. 19361942. doi:10.1002/cncr.20151

[36] R. Gorlick, A. G. Huvos, G. Heller, A. Aledo, G. P. Beardsley and J. H. Healey, "Expression of HER2/erbB-2 Correlates with Survival in Osteosarcoma," Journal of Clinical Oncology, Vol. 17, No. 9, 1999, pp. 2781-2788.

[37] T. Akatsuka, T. Wada, Y. Kokai, S. Kawaguchi, K. Isu and K. Yamashiro, "ErbB2 Expression Is Correlated with Increased Survival of Patients with Osteosarcoma," Cancer, Vol. 94, No. 5, 2002, pp. 1397-1404. doi:10.1002/cncr.10360

[38] T. Akatsuka, T. Wada, Y. Kokai, S. Kawaguchi, K. Isu and K. Yamashiro, "Over Expression of the HER-2 Oncogene Does Not Play a Role in High-Grade Osteosarcomas," European Journal of Cancer, Vol. 40, No. 7, 2004, pp. 963-970. doi:10.1016/j.ejca.2003.10.025

[39] D. P. Hughes, D. G. Thomas, T. J. Giordano, L. H. Baker and K. T. McDonagh, "Cell Surface Expression of Epidermal Growth Factor Receptor and Her-2 with Nuclear Expression of Her-4 in Primary Osteosarcoma," Cancer Research, Vol. 64, No. 6, 2004, pp. 2047-2053. doi:10.1158/0008-5472.CAN-03-3096

[40] D. P. Hughes, D. G. Thomas, T. J. Giordano, K. T. McDonagh and L. H. Baker, "Essential erbB Family Phosphorylation in Osteosarcoma as a Target for CI-1033 Inhibition," Pediatric Blood Cancer, Vol. 46, No. 5, 2006, pp. 614-623. doi:10.1002/pbc.20454

[41] M. A. Witlox, V. W. Van Beusechem, J. Grill, H. J. Haisma, G. Schaap and J. Bras, "Epidermal Growth Factor Receptor Targeting Enhances Adenoviral Vector Based Suicide Gene Therapy of Osteosarcoma," Journal of Gene Medicine, Vol. 4, No. 5, 2002, pp. 510-516. doi:10.1002/jgm.308

[42] Y. H. Wen, H. Koeppen, R. Garcia, L. Chiriboga, B. D. Tarlow and B. A. Peters, "Epidermal Growth Factor Receptor in Osteosarcoma: Expression and Mutational Analysis," Human Pathology, Vol. 38, No. 8, 2007, pp. 1184-1191. doi:10.1016/j.humpath.2007.01.002

[43] S. P. Chawla, V. S. Chua, L. Fernandez, D. Quon, A. Saralou and W. C. Blackwelder, "Phase I/II and Phase II Studies of Targeted Gene Delivery in Vivo: Intravenous Rexin-G for Chemotherapy-Resistant Sarcoma and Osteosarcoma," Molecular Therapy, Vol. 17, No. 9, 2009, pp. 1651-1657. doi:10.1038/mt.2009.126

[44] C. R. Dass, L. M. Khachigian and P. F. Choong, "c-Jun Knockdown Sensitizes Osteosarcoma to Doxorubicin," Molecular Cancer Therapeutics, Vol. 7, No. 7, 2008, pp. 1909-1912. doi:10.1158/1535-7163.MCT-08-0086

[45] P. M. Anderson, G. A. Wiseman, L. Erlandson, V. Rodriguez, B. Trotz and S. A. Dubansky, "Gemcitabine Radiosensitization after High-Dose Samarium for Osteoblastic Osteosarcoma," Clinical Cancer Research, Vol. 11, No. 1, 2005, pp. 6895-6900.

\section{doi:10.1158/1078-0432.CCR-05-0628}

[46] A. Mahajan, S. Y. Woo, D. G. Kornguth, D. Hughes, W. Huh and E. L. Chang, "Multimodality Treatment of Osteosarcoma: Radiation in a High-Risk Cohort," Pediatric Blood \& Cancer, Vol. 50, No. 5, 2008, pp. 976-982. doi:10.1002/pbc. 21451

[47] P. M. Anderson, G. A. Wiseman, A. Dispenzieri, C. A. Arndt, L. C. Hartmann and W. A. Smithson, "High-Dose Samarium-153 Ethylene Diamine Tetramethylene Phosphonate: Low Toxicity of Skeletal Irradiation in Patients with Osteosarcoma and Bone Metastases," Journal of Clinical Oncology, Vol. 20, No. 1, 2002, pp. 189-196. doi:10.1200/JCO.20.1.189

[48] D. E. Heron, A. Brufsky, S. Beriwal and M. Kurman, "Myelotoxicity of Samarium Sm 153 Lexidronam in Patients Receiving Prior Treatment with Chemotherapy or Radiotherapy," Annals of Oncology, Vol. 19, No. 9, 2008, pp. 1639-1643. doi:10.1093/annonc/mdn178

[49] C. MacLean, S. Newberry, M. Maglione, M. McMahon, V. Ranganath and M. Suttorp, "Systematic Review: Comparative Effectiveness of Treatments to Prevent Fractures in Men and Women with Low Bone Density or Osteoporosis," Annals of Internal Medicine, Vol. 148, No. 11, 2008, pp. 197-213.

[50] T. Iguchi, Y. Miyakawa, K. Saito, C. Nakabayashi, M. Nakanishi and H. Saya, "Zoledronate-Induced S Phase Arrest and Apoptosis accompanied by DNA Damage and Activation of the ATM/Chk1/cde25 Pathway in Human Osteosarcoma Cells," International Journal of Oncology, Vol. 31, 2007, pp. 285-291.

[51] B. Kubista, K. Trieb, F. Sevelda, C. Toma, F. Arrich and P. Heffeter, "Anticancer Effects of Zoledronic Acid against Anticancer Cells," Journal of Orthopaedic Research, Vol. 24, 2006, pp. 1145-1152. doi:10.1002/jor.20129

[52] A. McTiernan and J. S. Whelan, "A Phase II Study of Docetaxel for the Treatment of Recurrent Osteosarcoma," Sarcoma, Vol. 8, No. 2-3, 2004, pp. 71-76. doi: $10.1155 / 2004 / 762736$

[53] C. Laverdiere, E. A. Kolb, J. G. Supko, R. Gorlick, P. A. Meyers and R. G. Maki, "Phase II Study of Ecteinascidin 743 in Heavily Pretreated Patients with Recurrent Osteosarcoma," Cancer, Vol. 98, No. 4, 2003, pp. 832-840. doi:10.1002/cncr.11563

[54] S. J. Strauss, A. McTiernan and J. S. Whelan, "Late Relapse of Osteosarcoma: Implications for Follow-Up and Screening," Pediatric Blood Cancer, Vol. 43, No. 6, 2004, pp. 692-697. doi:10.1002/pbc.20154

[55] W. H. Meyer, C. B. Pratt, C. A. Poquette, B. N. Rao, D. M. Parham and N. M. Marina, "Carboplatin/Ifosfamide Window Therapy for Osteosarcoma: Results of the St Jude Children's Research Hospital OS-91 Trial," Journal of Clinical Oncology, Vol. 19, No. 1, 2001, pp. 171-182.

[56] C. A. Arndt, N. V. Koshkina, C. Y. Inwards, D. S. Hawkins, M. D. Krailo and D. Villaluna, "Inhaled GM-CSF for First Pulmonary Recurrence of Osteosarcoma; Immunologic and Surgical Findings," CTOS, 2010, Abstr 54-830406.

[57] A. J. Chou, M. D. Bell, C. Mackinson, R. Gupta, P. A. 
Meyers and R. Gorlick, "Phase Ib/IIa Study of Sustained Release Lipid Inhalation Targeting Cisplatin by Inhalation in the Treatment of Patients with Relapsed/Progressive Osteosarcoma Metastatic to the Lung," Journal of Clinical Oncology, Vol. 25, No. 18S, 2007, pp. 9525.

[58] B. Kempf-Bielack, S. S. Bielack, H. Jürgens, D. Branscheid, W. E. Berdel and G. U. Exner, "Osteosarcoma Relapse after Combined Modality Therapy: An Analysis of Unselected Patients in the Cooperative Osteosarcoma Study Group (COSS)," Journal of Clinical Oncology, Vol. 23, 2005, pp. 559-568. doi:10.1200/JCO.2005.04.063

[59] G. Bacci, A. Briccoli, A. Longhi, S. Ferrari, M. Mercuri and F. Faggioli, "Treatment and Outcome of Recurrent Osteosarcoma: Experience at Rizzoli in 235 Patients Initially Treated with Neoadjuvant Chemotherapy," Acta Oncologica, Vol. 44, No. 7, 2005, pp. 748-755. doi: $10.1080 / 02841860500327503$

[60] G. Bacci, A. Longhi, F. Bertoni, A. Briccoli, M. Versari and E. Pignotti, "Bone Metastases in Osteosarcoma Patients Treated with Neoadjuvant or Adjuvant Chemotherapy: The Rizzoli Experience in 52 Patients," Acta Orthopaedica, Vol. 77, No. 6, 2006, pp. 938-943. doi:10.1080/17453670610013268

[61] J. S. Miser, T. J. Kinsella, T. J. Triche, M. Tsokos, P. Jarosinski and R. Forquer, "Ifosfamide with Mesna Uroprotection and Etoposide: An Effective Regimen in the Treatment of Recurrent Sarcomas and Other Tumors of Children and Young Adults" Journal of Clinical Oncology, Vol. 5, No. 8, 1987, pp. 1191-1198.

[62] F. Navid, J. R. Willert, M. B. McCarville, W. Furman, A. Watkins and W. Roberts, "Combination of Gemcitabine and Docetaxel in the Treatment of Children and Young Adults with Refractory Bone Sarcoma," Cancer, Vol. 113, No. 2, 2008, pp. 419-425. doi:10.1002/cncr.23586

[63] M. Berger, G. Grignani, S. Ferrari, E. Biasin, P. A. del Brach and S. Aliberti, "Cyclophosphamide and Etoposide for Relapsed High-Risk Osteosarcoma Patients," Cancer, Vol. 115, No. 13, 2009, pp. 2980-2987. doi: $10.1002 /$ encr. 24368

[64] F. Fagioli, M. Aglietta, A. Tienghi, S. Ferrari, P. A. del Brach and E. Vassallo, "High-Dose Chemotherapy in the Treatment of Relapsed Osteosarcoma: An Italian Sarcoma Group Study," Journal of Clinical Oncology, Vol. 20, No. 8, 2002, pp. 2150-2156. doi:10.1200/JCO.2002.08.081

[65] E. C. van Dalen, J. W. van As and B. de Camargo, "Methotrexate for High-grade Osteosarcoma in Children and Young Adults. Cochrane Database of Systematic Reviews, No. 5, 2011, Article No. CD006325.

[66] N. Jaffe, R. Robertson, A. Ayala, S. Wallace, V. Chuang and T. Anzai, "Comparison of Intra-Arterial Cis-diamminedichloroplatinum II with High-Dose Methotrexate and Citrovorum Factor Rescue in the Treatment of Primary Osteosarcoma," Journal of Clinical Oncology, Vol. 3, No. 8, 1985, pp. 1101-1104.

[67] A. M. Goorin, M. Delorey and R. D. Gelber, "The Dana Farber Cancer Institute/The Children's Hospital Adjuvant Chemotherapy Trials for Osteosarcoma: Three Sequential Studies," Cancer Treatment Symposium, Vol. 3, 1985, pp. 155-159.
[68] G. Rosen, "Role of Chemotherapy in the Treatment of Primary Osteogenicsarcoma: A Five-Year Follow-Up of T-10 Neoadjuvant Chemotherapy," In: K. Kimura, Y.-M. Wang, Eds., Methotrexate in Cancer Therapy, Raven Press, New York, 1986, pp. 227-238.

[69] G. Bacci, F. Gherlinzoni, P. Picci, J. R. Van Horn, N. Jaffe and A. Guerra, "Doxorubicin-Methotrexate HighDose versus Doxorubicin-Methotrexate Moderate dose as Adjuvant Chemotherapy for Osteosarcoma of the Extremities: A Randomized Study," European Journal of Cancer and Clinical Oncology, Vol. 22, 1986, pp. 13371345. doi:10.1016/0277-5379(86)90142-2

[70] N. Delepine, G. Delepine, C. Jasmin, J. C. Desbois, H. Cornille and G. Mathé, "The Importance of Age and Methotrexate Dosage: Prognosis in Children and Young Adults with High grade Osteosarcoma," Biomedicine \& Pharmacotherapy, Vol. 42, No. 4, 1988, pp. 257-262.

[71] N. Graf, K. Winkler, M. Betlemovic, N. Fuchs and U. Bode, "Methotrexate Pharmakinetics and Prognosis in Osteosarcoma," Journal of Clinical Oncology, Vol. 12, No. 7, 1994, pp. 1443-1451.

[72] N. Jaffe and R. Gorlick, "High-Dose Methotrexate in Osteosarcoma: Let the Questions Surcease-Time for Final Acceptance," Journal of Clinical Oncology, Vol. 26, No. 27, 2008, pp. 4365-4366. doi:10.1200/JCO.2007.14.7793

[73] N. Jaffe, Eds., "Osteosarcoma: Review of the Past, Impact on the Future. The American Experience. Pediatric and Adolescent Osteosarcoma," Cancer Treatment and Research, Vol. 152, 2009, pp. 239-262.

[74] J. Bajpai, R. Kumar, V. Sreenivas, M. C. Sharma, S. A. Khan and S. Rastogi, "Prediction of Chemotherapy Response by PET-CT in Osteosarcoma: Correlation with Histologic Necrosis," Journal of Pediatric Hematology/ Oncology, Vol. 33, No. 7, 2011, pp. e271-e278.

[75] J. Bajpai, S. Gamnagatti, R. Kumar, V. Sreenivas, M. C. Sharma and S. A. Khan, "Role of MRI in Osteosarcoma for Evaluation and Prediction of Chemotherapy Response: Correlation with Histological Necrosis," Pediatric Radiology, Vol. 41, No. 4, 2011, pp. 441-450. doi:10.1007/s00247-010-1876-3

[76] J. Bajpai, M. Sharma, V. Sreenivas, R. Kumar, S. Gamnagatti and S. A. Khan, "VEGF Expression as a Prognostic Marker in Osteosarcoma," Pediatric Blood \& Cancer, Vol. 53, No. 6, 2009, pp. 1035-1039. doi: $10.1002 /$ pbc. 22178

[77] J. Bajpai, S. Gamanagatti, M. C. Sharma, R. Kumar, S. Vishnubhatla and S. A. Khan, "Noninvasive Imaging Surrogate of Angiogenesis in Osteosarcoma," Pediatric Blood \& Cancer, Vol. 54, No. 4, 2010, pp. 526-531.

[78] "The European and American Osteosarcoma Study Group: The EURAMOS I Trial," 2006. http://www.euramos.org

[79] J. K. Anninga, H. Gelderblom, M. Fiocco, J. R. Kroep, A. H. Taminiau and P. C. Hogendoorn, "Chemotherapeutic Adjuvant Treatment for Osteosarcoma: Where Do We Stand?" European Journal of Cancer, Vol. 47, No. 16, 2011, pp. 2431-2445. doi:10.1016/j.ejca.2011.05.030 
[80] B. Kempf-Bielack, S. S. Bielack, H. Jürgens, D. Branscheid, W. E. Berdel and G. U. Exner, "Osteosarcoma Relapse after Combined Modality Therapy: An Analysis of Unselected Patients in the Cooperative Osteosarcoma Study Group (COSS)," Journal of Clinical Oncology, Vol. 23, 2005, pp. 559-568. doi:10.1200/JCO.2005.04.063 